\title{
RETAIL MARGINS DURING RECESSION AND GROWTH
}

\author{
B. NOOTEBOOM and A.R. THURIK* \\ Research Institute for Small and Medium-Sized Business. 2701 A A Zoetermeer. The Netherlands
}

Received 24 July 1984

The influence of consumer spending on retail price setting behaviour is investigated in the context of a theory developed in previous research. The results indicate that the effect is not the same for growth and decline of spending.

\section{Introduction}

Nooteboom (1983) developed a theory to explain average percentage gross margin (the difference between sales and purchase value of retail sales, as a percentage of sales) per type of shop. ${ }^{1}$ The purpose of the present paper is (a) to present estimation results for a wide range of Dutch shop types for a recent period (1976-1982), (b) to analyse the effects of market dynamics on retail price setting behaviour in times of growing and of declining consumer spending.

Average percentage margin is explained as a mark-up on average percentage operating costs excluding a reward for shopkeepers labour. Nooteboom (1983) explains the height of the mark-up on the basis of the following factors:

- Average shop size: average percentage mark-up is inversely related to average sales size per shop. The rationale of this component of the model is that a higher average sales size requires a lower percentage of sales to achieve a given average reward for shopkeepers labour.

- Type of product and service level: a more varied range of products, slower moving products and a higher service level require a higher profit mark-up (supply side), and justify a higher mark-up due to greater dependence of customers on the retailer (demand side).

- Stage in the life-cycle of the retail formula: during the penetration phase (increasing market share) there is a bonus on novelty; during the phase of saturation this bonus falls away; during the phase of decline the profit mark-up shrinks due to the competition of novel types of trade. The life-cycle effect has been particularly prominent in the grocery trade, with its rise and decline of successive innovations: self service grocer, supermarkets, discount stores, specialty supermarkets and 'softdiscounts'. See Nooteboom (1984).

* The authors wish to acknowledge computing assistance provided by Mr. van Schaik, and the provision of data from a panel of shops organized by the Institute.

1 A shop type is a class of shops that are similar with respect to assortment of products sold, service level, extent of own production (packaging, meat cutting, bread bakery, repairs, etc.) and type of ownership (independent, chain store, cooperative). 
- Effect of the business cycle: the level of the percentage mark-up depends on the growth rate of consumer spending (in volume). The rationale is that in a contracting market, price competition is more intense, in the struggle for a larger share in a declining market to sustain sales volume, which leads to a lower average profit percentage.

The full model, including both life and business cycle, was estimated successfully, but only for the Dutch grocery trade, and only up to 1979.

\section{The present study}

The present study is concerned with a wide range of shop types in a recent period (1976-1982). In the Netherlands, consumer spending has been generally growing up to 1979 and declining since 1980 , and it is interesting to see whether the model stands up to these more recent conditions. In the previous study, the business cycle effect was estimated on the basis of fluctuations in the growth of spending. Now we have the opportunity to estimate the effect of different rates of both growth and decline. This also yields the opportunity to test for an asymmetric effect: a positive (or zero) effect during growth, which differs from a negative (or zero) effect during a decline of consumer spending. The first effect refers to inflationary profits during growth, and the second to a profit squeeze during recessions. The effects need not both occur, and they may be different in size. Also, we wish to investigate whether the effects differ between goods with a high frequency of purchase (foods) and goods with a low frequency (durables).

\section{Model specification}

The model is estimated according to the following specification:

$$
\begin{aligned}
\mu_{i t}= & \alpha_{0}+\alpha_{1} \kappa_{i t}+\alpha_{2}\left(1 / q_{i t}\right)+\alpha_{31} \epsilon_{i t}+\alpha_{32} \sigma_{i t}+\alpha_{41} \dot{c} d h_{i t}+\alpha_{42} \dot{c} d l_{i t} \\
& +\alpha_{43} \dot{c} g h_{i t}+\alpha_{44} \dot{c} g l_{i t}+u_{i t}, \text { where } \\
i \quad= & \text { index of the shop type, } \\
t \quad= & \text { index of the year, } \\
\mu \quad= & \text { average percentage gross margin, } \\
\kappa \quad= & \text { average percentage operating costs excluding a reward for shopkeepers labour, } \\
q \quad= & \text { average sales per shop in thousands of guilders at } 1975 \text { prices, } \\
\epsilon \quad= & \text { income elasticity for the products/services offered. For example, for groceries } \epsilon=0.5, \\
\sigma \quad= & \text { average stock lcvel as a percentage of sales, } \\
\dot{c} d h= & \text { percentage volume decline of consumer spending (negative growth) in shop types with high } \\
& \text { frequency goods (the variable is zero elsewhere), } \\
\dot{c} d l= & \text { decline of spending in the case of low frequency goods, } \\
\dot{c} g h= & \text { growth of spending in the case of high frequency goods, } \\
\dot{c} g l= & \text { growth of spending in the case of low frequency goods, } \\
u= & \text { stochastic disturbance term which is assumed to be homoskedastic and free from autocorrela- } \\
& \text { tion, }
\end{aligned}
$$


and where

- the constant $\alpha_{0}$ is included as a test: according to the theory there is no remainder in the form of a constant term, and $\alpha_{0}$ should be zero,

- the coefficient $\alpha_{1}$ is included as a test: according to the theory of the mark-up model, $\alpha_{1}$ should be unity,

- coefficient $\alpha_{2}$ represents the average basic reward for shopkeepers labour in prices of 1975 ,

- both $\epsilon$ and $\sigma$ are included in the present specification to decide which is the best indicator of the 'product/service'-effect on the profit mark-up,

- all 'percentage' variables are divided by 100 . This implies that $\alpha_{2}$ is expressed in tens of guilders at 1975 prices.

\section{Data}

The data were obtained for the period 1976-1982 ( 7 years), for 16 shop types, yielding a total of 112 observations. The source of the data was an ongoing panel of independent Dutch retailers called 'bedrijfssignaleringssysteem' (firm signalling system), which is operated by the Research Institute for Small and Medium Sized Business in the Netherlands. The number of participating firms per type of trade ranges between 12 and 309, with an average of 77. The shop types included in the study were:

High frequency goods: small self service gracers (superettes), supermarkets without a butchers shop, supermarkets with a butchers shop, greengrocers, liquor stores, druggists, flower shops.

Low frequency goods: men's clothes, women's clothes, mixed clothes shops, ornaments and watches, bicycle shops, furniture shops, home textiles shops, mixed furniture/textiles shops, shoe shops.

\section{Results and discussion}

The result of the estimation is as follows:

$$
\begin{aligned}
\mu_{i t}= & -\underset{(0.63)}{0.64}+\underset{(0.036)}{1.106} \kappa_{i t}+\underset{(180)}{1331}\left(1 / q_{i t}\right)+\underset{(0.73)}{0.83} \epsilon_{i t}+\underset{(2.17)}{6.75} \sigma_{i t} \\
& +\underset{(0.062)}{0.161} \dot{c} d h+\underset{(0.064)}{0.265} \dot{c} d l+\underset{(0.040)}{0.065} \dot{c} g h-\underset{(0.044)}{0.072} \dot{c} g l, \quad n=112, \quad R^{2}=0.976 .
\end{aligned}
$$

The figures between brackets are standard errors.

From the estimation results we see that:

- As postulated, there is no statistically significant remainder in the form of a constant term.

- In contrast with the theory, the coefficient of percentage operating costs $(\kappa)$ is not unity, but somewhat larger (approximately 1.1 ), and the excess is statistically significant.

- The estimated average reward for shopkeepers labour in $1975\left(\alpha_{2}\right)$ is approximately 13 thousand guilders. This is approximately equal to the legal minimum wage of employees (net of tax and social security contributions). In the previous study [Nooteboom (1983)] the estimate for 1970 (with a different data source) was approximately 7.5 thousand guilders, which was also about equal to the (gross) minimum wage in that year. 
$\sigma$ (average percentage stock level) appears to be a better indicator than $\epsilon$ (income elasticity) of the 'product/service' effect on the profit mark-up. We shall not further discuss this result here.

- The coefficients for the business-cycle effect are significant when there is a decline (negative growth) of consumer spending, and the effect is not significantly different between high-frequency goods $(\dot{c} d h)$ and low-frequency goods $(\dot{c} d l)$. If we take the average value of the 2 coefficients for negative growth $(0.21)$, the size of the effect can be illustrated as follows: when there is a decline of consumer spending of $2 \%$ per annum (in volume), the average percentage profit mark-up will, ceteris paribus, be almost half a percentage point lower than during zero growth of spending.

- The coefficients for the business-cycle effect are not significantly different from zero when there is an increase (positive growth) of consumer spending. Furthermore, the coefficients have opposite signs for high-frequency goods $(\dot{c} g h)$ and low-frequency goods $(\dot{c} g l)$.

\section{Conclusions}

From the point of view of method, our conclusion is that the theory as a whole stands up fairly well to a change of data source, set of shop types and period studied. Generally, the coefficients are in agreement with the theory, statistically significant, stable, and consistent between different data sources.

From the point of view of content and implications, the main purpose of the present study was to investigate the business-cycle effect in more detail. The present results indicate that there is a significant squeeze of profit margins during a recession, with no significant indication of a difference in effect between high-frequency and low-frequency goods. During a decline of consumer spending of $2 \%$, average percentage net profit is, ceteris paribus, almost half a percentage point lower than during zero growth of spending. Such a decline in spending has occurred in the Netherlands since 1980. Half a percentage point difference may not seem much, but it is: at a percentage net profit between 3 and $5 \%$, a decline by half a percentage point is a decline by 10 to $17 \%$. As a result, recessions can be seen to hit retailing hard, with a decline of sales volume and a decline of profit margins when growth turns into decline. We note that according to the model the level of percentage profit is affected by the growth rate of spending. The net profit rate declines when growth of spending switches to a decline of spending (as happened in the Netherlands in 1980) or when the recession deepens to an increased decline of spending (1981). When the decline of spending levels off to a constant rate (1982, 1983), the profit margin levels off on a low level. One might also expect the converse effect of an inflationary rise of profit margins when spending accelerates to higher levels of growth. The present results do not support that expectation. The results indicate an asymmetry in the business-cycle effect: a profit squeeze in recessions, but no profit inflation during growth.

Apart from certain adjustments made in the grocery trade, the present study does not include the life cycle effect. Further study is needed to include this effect. Furthermore, the assumption of absence of homoskedasticity and autocorrelation in the disturbance term may not be justified. Follow-up studies will deal with these matters.

\section{References}

Nooteboom, B., 1983, A mark-up model of retail margins, Research paper 8204 (Research Institute for Small and Medium-sized Business, Zoetermeer) Aplied Economics, forthcoming.

Nooteboom, B., 1984, Innovation, life cycle and the share of independents: Cases from retailing. International Small Business Journal, forthcoming. 